\title{
The Relationship Between Anthropometric Measures, Blood Gases, and Lung Function in Morbidly Obese White Subjects
}

\author{
Anne-Marie Gabrielsen • May Brit Lund • \\ Johny Kongerud • Karl Erik Viken • Jo Røislien • \\ Jøran Hjelmesæeth
}

Published online: 19 November 2010

(C) The Author(s) 2010. This article is published with open access at Springerlink.com

\begin{abstract}
Background Obesity may cause adverse effects on the respiratory system. The main purpose of this study was to investigate how various measures of obesity are related to arterial blood gases and pulmonary function.

Methods This is a cross-sectional study of consecutive morbidly obese patients with normal lung function. Blood gas samples were taken from the radial artery after 5 min of rest with subjects sitting upright. Lung function measurements included dynamic spirometry, static lung volumes, and gas diffusing capacity.

Results The 149 patients (77\% women) had a mean (SD) age of 43 years (11 years) and BMI of $45.0 \mathrm{~kg} / \mathrm{m}^{2}\left(6.3 \mathrm{~kg} / \mathrm{m}^{2}\right)$. The mean expiratory reserve volume (ERV) was less than half (49\%) of predicted value, whilst most other lung function values were within predicted range. Forty-two patients had an abnormally low pO2 value $(<10.7 \mathrm{kPa}[80 \mathrm{mmHg}])$, while eight patients had a high $\mathrm{pCO} 2$ value $(>6.0 \mathrm{kPa}[45 \mathrm{mmHg}])$.
\end{abstract}

A.-M. Gabrielsen · J. Røislien · J. Hjelmesæth $(\bowtie)$

The Morbid Obesity Center, Vestfold Hospital Trust,

Box 2168, 3103, Tønsberg, Norway

e-mail: joran.hjelmeseth@siv.no

A.-M. Gabrielsen · K. E. Viken

Medical Department, Vestfold Hospital Trust,

Box 2168, 3103, Tønsberg, Norway

M. B. Lund $\cdot$ J. Kongerud

Department of Respiratory Medicine,

Oslo University Hospital Rikshospitalet,

0027, Oslo, Norway

J. Røislien

Department of Biostatistics, Institute of Basic Medical Sciences,

University of Oslo,

Oslo, Norway
All anthropometric measures correlated significantly with decreasing $\mathrm{pO} 2$ and increasing $\mathrm{pCO} 2$ (all $P$ values $<0.05$ ). BMI, neck circumference (NC), and waist circumference (WC) were negatively correlated with ERV $(r=-0.25,-0.19$, -0.21 , respectively, all $P$ values $<0.05$ ). Multiple linear regression showed that $\mathrm{BMI}, \mathrm{WC}$, and $\mathrm{NC}$ were significantly associated with $\mathrm{pO} 2$ after adjustments for age, gender, and pack-years (all $P$ values $<0.001$ ). The models explained 34 $36 \%$ of the variations in $\mathrm{pO} 2$. BMI, NC, and $\mathrm{WC}$ were also significantly associated with $\mathrm{pCO} 2$ (all $P$ values $<0.05$ ). There was no significant association between waist-to-hip ratio and blood gases (both $P$ values $>0.27$ ).

Conclusions Both central and overall obesity were associated with unfavorable blood gases and low ERV.

Keywords Lung function · Anthropometry $\cdot$ Obesity $\cdot$ Blood gases

$\begin{array}{ll}\text { Abbreviation } \\ \text { COPD } & \text { Chronic obstructive pulmonary disease } \\ \text { DLCO } & \text { Diffusing capacity for carbon monoxide } \\ \text { ERV } & \text { Expiratory reserve volume } \\ \text { FEV1 } & \text { Forced expiratory volume the first second } \\ \text { FRC } & \text { Functional residual capacity } \\ \text { FVC } & \text { Forced vital capacity } \\ \text { HC } & \text { Hip circumference } \\ \text { IC } & \text { Inspiratory capacity } \\ \text { ITGV } & \text { Intrathoracic gas volume } \\ \text { NC } & \text { Neck circumference } \\ \text { TLC } & \text { Total lung capacity } \\ \text { VA } & \text { Alveolar lung volume } \\ \text { VC } & \text { Vital capacity } \\ \text { WC } & \text { Waist circumference } \\ \text { WHR } & \text { Waist-to-hip ratio } \\ \text { RV } & \text { Residual volume }\end{array}$

\section{Abbreviation}

COPD Chronic obstructive pulmonary disease

DLCO Diffusing capacity for carbon monoxide

ERV Expiratory reserve volume

FEV1 Forced expiratory volume the first second

FRC Functional residual capacity

FVC Forced vital capacity

Hip circumference

IC Inspiratory capacity

ITGV Intrathoracic gas volume

NC Neck circumference

TLC Total lung capacity

Alveolar lung volume

VC Vital capacity

WC Waist circumference

RV Residual volume 


\section{Introduction}

Obesity may cause adverse effects on the respiratory system due to alterations in gas exchange, respiratory mechanics, muscular endurance, and respiratory control [1]. These effects may be linked to a variety of comorbidities such as pulmonary hypertension, diastolic dysfunction, and coronary heart disease. Obesity may also lead to respiratory failure known as obesity hypoventilation syndrome [1]. Pulmonary gas exchange impairment at rest may increase the risk of post-operative pulmonary complications and have negative impact on obesity-related comorbidities.

It has been shown that obesity reduces thoracic wall compliance by restricting diaphragm movement and thoracic cage expansion [2]. Lung compliance is also reduced due to increased blood volume and a combination of alveolar collapse and airway closing in the lung basis [3]. The effects of obesity on total lung capacity (TLC) and vital capacity (VC) are modest, whereas functional residual capacity (FRC) and particularly expiratory reserve volume (ERV) may be severely decreased [1, 4-6]. An observational study of 37 morbidly obese patients showed that massive weight loss following bariatric surgery was associated with a significant improvement of ERV [7].

The effects of various patterns of obesity on pulmonary function have been studied. In obese males, forced vital capacity (FVC), forced expiratory volume (FEV1), and TLC were lower in those with android obesity (i.e., upper body obesity) than in those with gynecoid obesity (i.e., lower body obesity) [8]. It has also been suggested that waist-to-hip ratio (WHR), rather than BMI, explains a large part of the variance in pulmonary gas exchange $[9,10]$. Current literature is scarce about the possible relationship between various levels of obesity and pulmonary gas exchange. If increasing levels of extreme obesity have detrimental effects on pulmonary gas exchange, this might have prognostic and therapeutic implications. We aimed to investigate how various measures of overall and abdominal obesity are related to arterial blood gases and pulmonary function in a population of morbidly obese patients with normal lung function.

\section{Material and Methods}

\section{Study Design and Population}

This is a cross-sectional analysis of baseline data from the non-randomized controlled MOBIL study (Morbid Obesity treatment, Bariatric surgery versus Intense Lifestyle intervention; Clinical Trials.gov number NCT0027314), the primary aim of which was to compare the effects of lifestyle intervention and bariatric surgery on various comorbidities. The study design, methods, and population have been described in detail [11]. Briefly, 224 adult morbidly obese subjects (BMI $\geq 40$ or $\geq 35 \mathrm{~kg} / \mathrm{m}^{2}$ with a weight-related comorbidity), predominantly of European descent, were consecutively screened at our regional tertiary care center. After exclusion of 47 subjects who declined to participate or who had heavy comorbidities, 177 subjects were found potentially eligible for either lifestyle intervention or bariatric surgery. As the aim of this substudy was to explore the specific effects of obesity on blood gases and lung function, 22 subjects with chronic obstructive pulmonary disease (FEV1/FVC $<70 \%)$ [12] and six subjects with restrictive lung function impairment (FVC $<80 \%$ of predicted value and TLC $<80 \%$ of predicted value) [13] were excluded from further analyses. The remaining 149 subjects were defined as having normal lung function and were included in the analysis.

All participants gave informed written consent before enrolment. The study was approved by the Regional Ethics Committee for Medical Research (S-05715).

\section{Data Source and Measurements}

All subjects were examined by a physician. Demographic data and medical history, including smoking habits (recorded as pack-years), and use of bronchodilators were recorded. Height, weight, neck circumference (NC), waist circumference (WC), and hip circumference (HC) were measured with subjects in an upright position wearing light clothes and no shoes. Indexes were calculated for BMI (weight divided by the square of height, kilograms per square meter $\left(\mathrm{kg} / \mathrm{m}^{2}\right)$ ) and WHR (WC divided by HC). NC was measured at the cricoid cartilage and $\mathrm{WC}$ at the level midway between the lowest rib margin and the iliac crest.

Blood gas samples were taken from the radial artery after at least $5 \mathrm{~min}$ of rest and with the subjects in a sitting position. The sampling was carried out by either a physician (AMG) or two experienced nurses. For analyses we used an ABL 735 Radiometer (Copenhagen, Denmark) calibrated in accordance with the manufacturer's specifications. Arterial blood gas values for $\mathrm{pO} 2<10.7 \mathrm{kPa}$ (80 $\mathrm{mmHg}$ ) and for $\mathrm{pCO} 2>6.0 \mathrm{kPa}(45 \mathrm{mmHg})$ were defined as abnormal [14].

Lung function measurements included dynamic spirometry, static lung volumes, and gas diffusion capacity. All tests were carried out by two experienced nurses according to the guidelines recommended by the ATS-ERS task force [15-17] and with subjects sitting in an upright position wearing a nose clip. The Jaeger Master Lab (Eric Jaeger, Wurzburg, Germany) was used in all tests and was calibrated daily using a 1-L syringe. Recorded variables were: FVC, FEV1, FEV1/FVC, diffusion capacity for carbon monoxide (DLCO), DLCO divided by alveolar lung 
volume (DLCO/VA), TLC, VC, inspiratory capacity (IC), intrathoracic gas volume (ITGV), ERV, and residual volume (RV).

The reference values for FVC, FEV1, DLCO, TLC, VC, IC, ITGV, and RV are those recommended by the European Respiratory Society (ERS) [13]. These reference values have been derived from studies of healthy, non-smoking adults of European descent [13]. However, since the ERS offers no reference values for ERV, the Jaeger Master Lab reference values were used instead. Sixteen lung volume tests were rejected (12 due to technical problems and four due to compliance problems), and one single breath test was rejected (due to non-compliance). All tests were carried out between 9 and 10A.M. No bronchodilator drug was allowed prior to lung function testing.

\section{Statistical Analysis}

Independent samples $t$ test or Mann-Whitney test were used for the comparison of continuous data, whereas Chi-square test was used for categorical data. Spearman's correlations were calculated to assess bivariate relationships between anthropometric measures, blood gases, and lung function tests. Multiple linear regression analyses were used to assess the effect of each anthropometric measure on arterial blood gases after adjustment for confounding factors (age, gender, pack-years). We fitted eight separate multiple linear regression models with either $\mathrm{pO} 2$ or $\mathrm{pCO} 2$ as the dependent variable, and either BMI, NC, WC, or WHR as the independent variable adjusted for confounders. No violation of the assumptions of normality or multicollinearity was revealed in the models. Two-tailed $P$ values are reported, with $P$ values below 0.05 considered statistically significant. Semi-partial (part) correlation coefficients were squared in order to estimate the percentage of total variance in the dependent variable explained by a given independent variable. The analyses were carried out using SPSS 16.0 (SPSS, Chicago, IL).

\section{Results}

Demographic, clinical, and anthropometric characteristics of the 149 morbidly obese patients are shown in Table 1 . Forty subjects $(27 \%)$ had physician-diagnosed asthma and had been prescribed brochodilators; 14 used on-demand short acting bronchodilators, while 26 used the combination of inhaled steroids and long acting beta-2-agonists.

The spirometry results, lung volumes, and blood gases are shown in Table 2. All lung function values except ERV, ITGV, and IC were within predicted range. The individual $\mathrm{pO} 2$ and $\mathrm{pCO} 2$ values ranged from $7.7 \mathrm{kPa}(58 \mathrm{mmHg})$ to $15.3 \mathrm{kPa}(115 \mathrm{mmHg})$ and from $3.6 \mathrm{kPa}(27 \mathrm{mmHg})$ to
Table 1 Demographic, anthropometric, and clinical characteristics of 149 morbidly obese patients

\begin{tabular}{lc}
\hline Variables & Values \\
\hline Females & $114(77)$ \\
Age [years] & $43(11)$ \\
Weight $[\mathrm{kg}]$ & $130(23)$ \\
BMI $\left[\mathrm{kg} / \mathrm{m}^{2}\right]$ & $45.0(6.3)$ \\
Neck circumference $[\mathrm{cm}]$ & $42(4)$ \\
Waist circumference $[\mathrm{cm}]$ & $133(14)$ \\
Waist-to-hip ratio & $0.97(0.09)$ \\
Bronchodilator medication & $40(27)$ \\
Never-smokers & $61(41)$ \\
Pack-years & $9(13)$ \\
\hline
\end{tabular}

Values are given as mean (SD) or $n(\%)$

$6.5 \mathrm{kPa}(49 \mathrm{mmHg})$, respectively. Forty-two patients $(28 \%)$ had abnormally low pO2 values $(<10.7 \mathrm{kPa}[80 \mathrm{mmHg}])$ and eight patients $(5 \%)$ had abnormally high $\mathrm{pCO} 2$ values $(>6.0 \mathrm{kPa}[45 \mathrm{mmHg}])$.

$\mathrm{BMI}, \mathrm{NC}$, and WC correlated significantly and negatively with ERV $(r=-0.25,-0.19$ and -0.21 , all $p<0.05)$, while NC correlated significantly and negatively with $\mathrm{VC}$ $(r=-0.23, p=0.007)$. WHR did not correlate significantly with any lung volume index, and no significant correlations were observed between anthropometrics measures and IC or RV (data not shown).

Table 2 Lung function and arterial blood gases in 149 morbidly obese patients

\begin{tabular}{lr}
\hline Variables & \multicolumn{2}{l}{ Values } \\
\hline Spirometry & $103(15)$ \\
Forced vital capacity & $97(15)$ \\
Forced expiratory volume the first second & \\
Gas diffusing capacity & $91(14)$ \\
Diffusing capacity for carbon monoxide [DLCO] & $105(16)$ \\
DLCO divided by alveolar lung volume & \\
Static lung volumes & $98(12)$ \\
Total lung capacity & $101(15)$ \\
Vital capacity & $123(22)$ \\
Inspiratory capacity & $78(16)$ \\
Intrathoracic gas volume & $49(34)$ \\
Expiratory reserve volume & $96(28)$ \\
Residual volume & \\
Blood gases and pH & $5.2 / 39(0.5 / 4)$ \\
pCO2 [kPa/mmHg] & $11.5 / 87(1.5 / 11)$ \\
pO2 [kPa/mmHg] & $7.41(0.02)$ \\
pH &
\end{tabular}

Except for blood gases, values are referred as "percent predicted" and given as mean $(\mathrm{SD})$ 

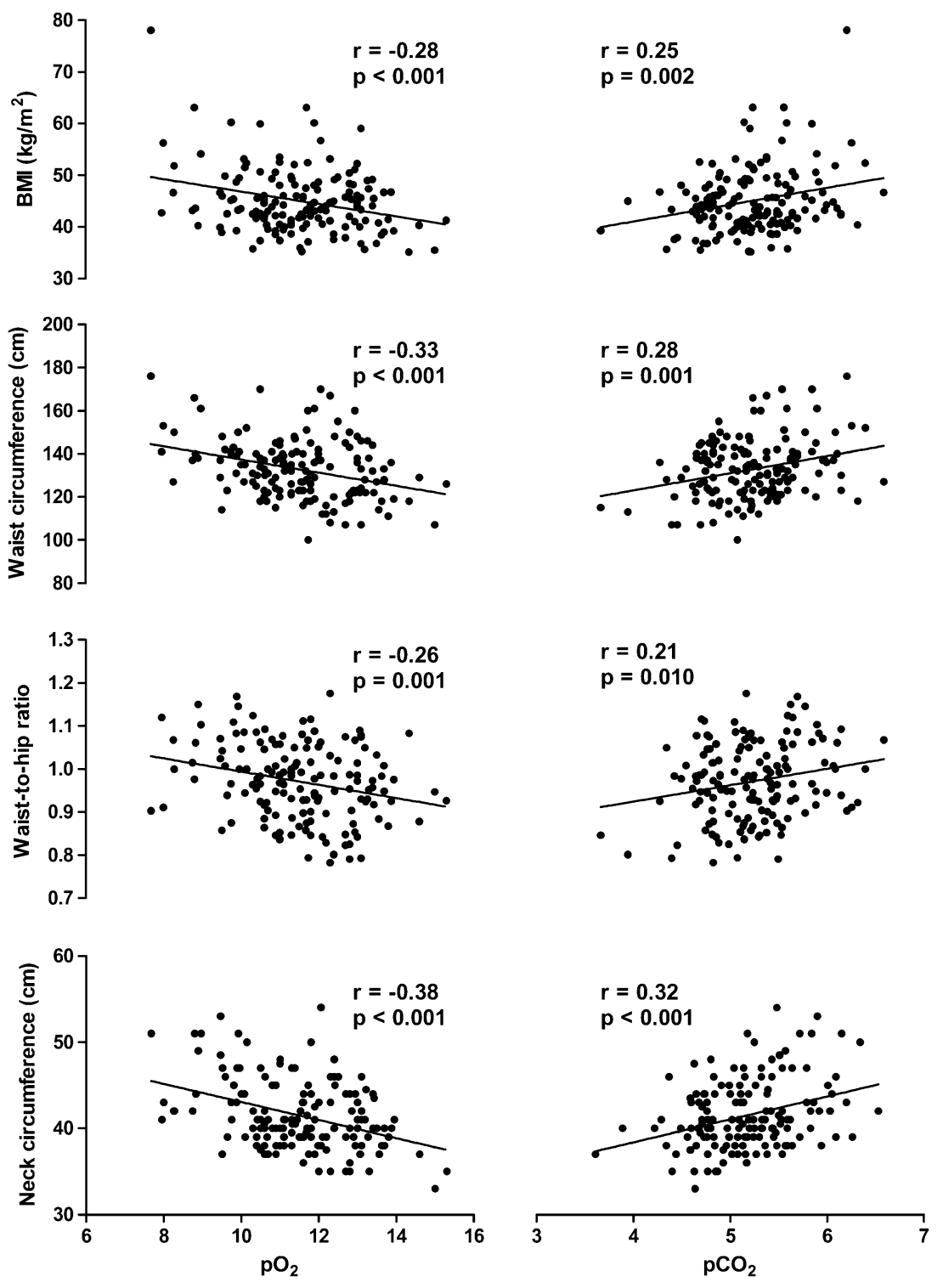

Fig. 1 The scatter plots show the relationship between anthropometric measures and blood gases

Figure 1 shows that all anthropometric measures correlated significantly with decreasing $\mathrm{pO} 2$ (all $P$ values $<0.01$ ), and increasing pCO2 (all $P$ values $<0.05$ ).

ERV and RV correlated significantly with $\mathrm{pO} 2$ and pCO2 (Fig. 2).

The multiple linear regression analyses showed that increasing levels of BMI, WC, and $\mathrm{NC}$ were significantly associated with decreasing $\mathrm{pO} 2$ after adjustments for age, gender, and pack-years (Tab 3). The three multivariate models explained $34-36 \%$ of the variation in pO2. Based on part correlations BMI explained $9 \%$, and $\mathrm{NC}$ and $\mathrm{WC}$ explained $6 \%$ of the variations in $\mathrm{pO} 2$.

Multiple linear regression (Table 3) showed that increasing BMI, NC, and WC were significantly associated with increasing pCO2. The three models explained $20-23 \%$ of the variation in $\mathrm{pCO} 2$. Based on part correlations $\mathrm{BMI}$ explained $6 \%$, and $\mathrm{NC}$ and $\mathrm{WC}$ explained $3 \%$ of the variations in $\mathrm{pCO} 2$. There were no significant associations between WHR and blood gases in the multivariable analyses.

\section{Discussion}

Key Results

The main and novel findings of this study are that both measures of overall (BMI) and central obesity (WC, NC) were significantly associated with lower $\mathrm{pO} 2$ and higher pCO2 among morbidly obese subjects with normal lung function. In addition, $\mathrm{BMI}, \mathrm{NC}$, and $\mathrm{WC}$ correlated negatively with ERV. 

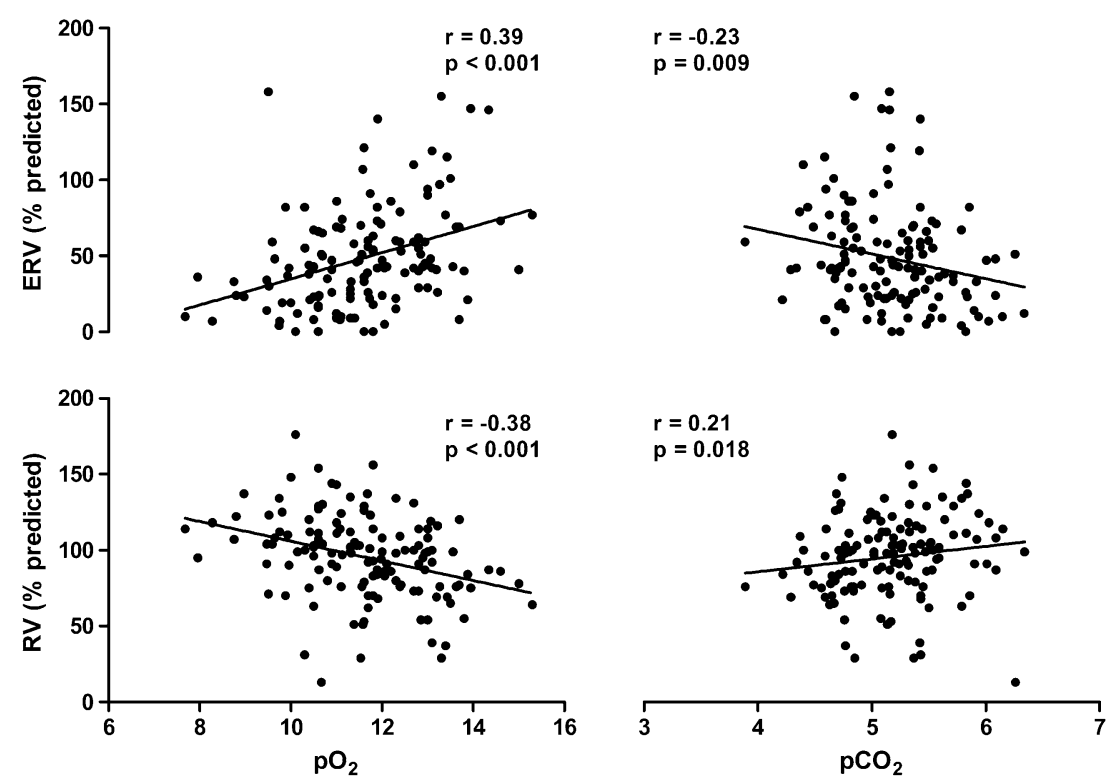

Fig. 2 The scatter plots show the relationship between expiratory reserve volume, residual volume, and blood gases

\section{Interpretation}

Our results are partly in contrast to those of Zavorsky et al. [9] who found that increasing WHR, but not BMI, was associated with detrimental changes in blood gas values. This discrepancy might have several explanations. Firstly, the previous study was small $(n=25)$ and included a heterogeneous sample of subjects with either normal $(n=$ 18 ) or abnormal $(n=7)$ lung function, but the analysis was not stratified according to lung function. Conversely, we examined 149 subjects, all with normal lung function. Secondly, in contrast to our study, clinically relevant confounding factors were neither addressed nor adjusted for in the previous study. Notably, we too could demonstrate statistically significant associations between WHR and blood gases in the univariate analyses, but these associations did not remain significant after adjustment for gender, age, and pack-years.

Our findings partly confirm the preliminary results from a cross-sectional study of 76 morbidly obese Chinese subjects that showed a significant association between BMI and blood gases [18]. Our results extend those findings to be valid in white morbidly obese patients independent of confounding factors. No measure of central obesity was addressed in the Chinese study.

Another more recent cross-sectional study of 150 morbidly obese Chinese adults with normal lung function demonstrated that only WC - in contrast to BMI and WHR - was associated with reductions in FEV1, FVC, TLC, and VC [19]. However, this study did not address the relationship between anthropometric measures and arterial blood gases.

Table 3 The relationship between various anthropometric measures and arterial blood gases in 149 morbidly obese subjects with normal lung function

\begin{tabular}{|c|c|c|c|c|}
\hline Dependent variables & Independent variables & Standardized beta & $P$ values & $R$-square \\
\hline \multirow[t]{4}{*}{ pO2 } & BMI & -0.292 & $<0.001$ & 0.36 \\
\hline & $\mathrm{NC}$ & -0.317 & $<0.001$ & 0.34 \\
\hline & WC & -0.270 & $<0.001$ & 0.36 \\
\hline & WHR & -0.096 & 0.268 & 0.29 \\
\hline \multirow[t]{4}{*}{$\mathrm{pCO} 2$} & BMI & 0.250 & 0.001 & 0.23 \\
\hline & $\mathrm{NC}$ & 0.225 & 0.023 & 0.20 \\
\hline & WC & 0.205 & 0.014 & 0.20 \\
\hline & WHR & 0.031 & 0.739 & 0.17 \\
\hline
\end{tabular}

Each anthropometric measure was adjusted for age, gender, and pack-years in eight separate multiple linear regression analyses

$B M I$ denotes body mass index, $N C$ neck circumference, $W C$ waist circumference, $W H R$ waist-to-hip ratio 


\section{Possible Mechanisms}

Abdominal fat raises intra-abdominal pressure causing cephalad movement of the diaphragm, and thus reducing chest volume. Morbidly obese subjects have an abnormally high alveolar-to-arterial oxygen partial pressure difference and reduced pO2 [9, 10], which reflects a ventilationperfusion mismatch as the lower parts of the lungs are underventilated and overperfused in obese subjects. Accordingly, profound weight loss after bariatric surgery has been associated with increased pO2 [7, 10]. Both WC and BMI reflect the amount of abdominal fat [20], and consequently increasing BMI and WC may be associated with atelectases and ventilation-perfusion mismatching, which may have an impact on blood gases.

In accordance with a previous study of morbidly obese patients, most lung function values were within predicted range whilst the mean ERV was less than $50 \%$ of predicted value [21].

Further, ERV was significantly correlated with BMI, NC, and WC. A decrease in ERV may lead to a decrease in FRC which in turn may fall below closing volume. Thus, morbidly obese subjects breathe near their residual volume. The collapse of small airways leads to increasing V/Q mismatch and hypoxia as described above. The relationship between reduced ERV and hypoxia in morbidly obese subjects has previously been shown [7]. In a study aimed to assess the effects of BMI on lung volumes [22], FRC and ERV were found to decrease exponentially with increasing BMI, and the greatest effects were on subjects with BMI $>30 \mathrm{~kg} / \mathrm{m}^{2}$. Notably, both FRC and ERV were significantly lower in moderately obese women and men (BMI, 30-35 kg/m ${ }^{2}$ ) than in their normal weight counterparts (BMI, $20-25 \mathrm{~kg} / \mathrm{m}^{2}$ ) of comparable age. In this way, even moderate obesity lead to decreased ERV which may affect blood gases.

Notably, although we excluded patients with abnormal lung function from the present analysis, one out of four patients $(27 \%)$ had been prescribed bronchodilator drugs due to asthma as diagnosed by their physician. This finding is in line with a previous study which reported a prevalence of asthma of $24 \%$ among morbidly obese subjects [21]. Several biological mechanisms may explain the relationship between asthma and obesity including those referred above [23].

\section{Generalizability and Possible Implications}

Our study demonstrates that in morbidly obese subjects, increasing levels of obesity are associated with worsening of blood gases. This could imply that clinicians should use spirometry and blood gas analyses to identify morbidly obese patients at particularly high risk for post-operative complications - for instance after bariatric surgery. Conse- quently, it might be wise to measure lung function and blood gases routinely in this patient group.

\section{Limitations}

Our study has limitations. Firstly, the cross-sectional design is unsuitable for establishing a cause-effect relationship. Secondly, our results may not be valid in non-white populations. Finally, we cannot exclude the possibility that the referral of patients to a tertiary care center might have introduced a sampling bias which may limit the generalizability of our results.

\section{Conclusion}

Our study of white morbidly obese subjects with normal lung function, demonstrates that increasing levels of BMI, $\mathrm{WC}$, and $\mathrm{NC}$ are significantly associated with decreasing pO2 and increasing pCO2 even after adjustments for age, gender, and pack-years. In addition, both central and overall obesity are associated with low ERV.

Acknowledgements We acknowledge the help from Dag Hofsø in designing the figures, and Berit Mossing Bjørkås, Heidi Omre Fon, Liv Randi Alu Andersen, and Elda Furulund Borg for their assistance with sampling and logistics. Thanks are due to Matthew McGee for proofreading the manuscript. Finally, we greatly acknowledge the patients who participated in the study.

Conflict of Interest No potential conflicts of interest relevant to this article were reported.

Open Access This article is distributed under the terms of the Creative Commons Attribution Noncommercial License which permits any noncommercial use, distribution, and reproduction in any medium, provided the original author(s) and source are credited.

\section{References}

1. Bickelmann AG, Burwell CS, Robin ED, et al. Extreme obesity associated with alveolar hypoventilation; a Pickwickian syndrome. Am J Med. 1956;21:811-18.

2. Naimark A, Cherniack RM. Compliance of the respiratory system and its components in health and obesity. J Appl Physiol. 1960; $15: 377-82$.

3. Parameswaran K, Todd DC, Soth M. Altered respiratory physiology in obesity. Can Respir J. 2006;13:203-10.

4. Kress JP, Pohlman AS, Alverdy J, et al. The impact of morbid obesity on oxygen cost of breathing (VO(2RESP)) at rest. Am J Respir Crit Care Med. 1999;160:883-6.

5. Koenig SM. Pulmonary complications of obesity. Am J Med Sci. 2001;321:249-79.

6. Laaban JP, Cassuto D, Orvoen-Frija E, et al. Respiratory complications of massive obesity. Rev Prat. 1992;42:469-76.

7. Vaughan RW, Cork RC, Hollander D. The effect of massive weight loss on arterial oxygenation and pulmonary function tests. Anesthesiology. 1981;54:325-8. 
8. Collins LC, Hoberty PD, Walker JF, et al. The effect of body fat distribution on pulmonary function tests. Chest. 1995;107:1298302.

9. Zavorsky GS, Murias JM, Kim dJ, et al. Waist-to-hip ratio is associated with pulmonary gas exchange in the morbidly obese. Chest. 2007;131:362-7.

10. Zavorsky GS, Hoffman SL. Pulmonary gas exchange in the morbidly obese. Obes Rev. 2008;9:326-39.

11. Hofso D, Ueland T, Hager $\mathrm{H}$, et al. Inflammatory mediators in morbidly obese subjects: associations with glucose abnormalities and changes after oral glucose. Eur J Endocrinol. 2009;161:451-8.

12. GOLD Guidelines. Executive Summary: Global Strategy for Diagnosis, Management, and Prevention of COPD 2010 (http:// www.goldcopd.org/Guidelineitem.asp?11=2\&12=1\&intId=2180)

13. Quanjer PH, Tammeling GJ, Cotes JE, et al. Lung volumes and forced ventilatory flows. Report working party standardization of lung function tests, European community for steel and coal. Official statement of the European respiratory society. Eur Respir J Suppl. 1993;16:5-40.

14. Williams AJ. ABC of oxygen: assessing and interpreting arterial blood gases and acid-base balance. BMJ. 1998;317:1213-16.

15. Miller MR, Hankinson J, Brusasco V, et al. Standardisation of spirometry. Eur Respir J. 2005;26:319-38.

16. Wanger J, Clausen JL, Coates A, et al. Standardisation of the measurement of lung volumes. Eur Respir J. 2005;26:511-22.
17. MacIntyre N, Crapo RO, Viegi G, et al. Standardisation of the single-breath determination of carbon monoxide uptake in the lung. Eur Respir J. 2005;26:720-35.

18. Chiang A, Mehrishi S, Ganaraj J et al. Relationship between body mass index and arterial blood gases. Chest. 2003:123S4S.

19. Wei YF, Wu HD, Chang CY, et al. The impact of various anthropometric measurements of obesity on pulmonary function in candidates for surgery. Obes Surg. 2010;20:589-94.

20. Janssen I, Heymsfield SB, Allison DB, et al. Body mass index and waist circumference independently contribute to the prediction of nonabdominal, abdominal subcutaneous, and visceral fat. Am J Clin Nutr. 2002;75:683-8.

21. Saliman JA, Benditt JO, Flum DR, et al. Pulmonary function in the morbidly obese. Surg Obes Relat Dis. 2008;4:632-9.

22. Jones RL, Nzekwu MM. The effects of body mass index on lung volumes. Chest. 2006;130:827-33.

23. Shore SA. Obesity and asthma: possible mechanisms. J Allergy Clin Immunol. 2008;121:1087-93.

Clinical Trials.gov number NCT0027314 